\title{
Nonlinear Free Vibrations of C-C-SS-SS Symmetrically Laminated Carbon Fiber Reinforced Plastic (CFRP) Rectangular Composite Plates
}

\author{
Zakaria Zergoune', Bilal Harras', Rhali Benamar ${ }^{2}$ \\ ${ }^{1}$ Laboratoire de Génie Mécanique, Faculté des Sciences et Techniques, Fez, Morocco \\ ${ }^{2}$ Laboratoire d'Études et de Recherches en Simulation, Université Med V Rabat, École Mohammadia \\ d'Ingénieurs, Rabat, Morocco \\ Email: zergoune.uni@gmail.com, harrasbilal@yahoo.fr, $\underline{\text { rhali.benamar@gmail.com }}$
}

Received 5 February 2015; accepted 23 February 2015; published 27 February 2015

Copyright (C) 2015 by authors and Scientific Research Publishing Inc.

This work is licensed under the Creative Commons Attribution International License (CC BY). http://creativecommons.org/licenses/by/4.0/

\section{(c) (i) Open Access}

\begin{abstract}
The purpose of this paper is to apply the theoretical model developed in References [1]-[6] in order to analyze the geometrically nonlinear free dynamic response of C-C-SS-SS rectangular CFRP symmetrically laminated plates so as to investigate the effect of nonlinearity on the nonlinear resonance frequencies, the nonlinear fundamental mode shape and associated bending stress patterns at large vibration amplitudes. Various values of the plate aspect ratio and the amplitude of vibrations will be considered, and useful numerical data also are provided.
\end{abstract}

Keywords

CFRP, C-C-SS-SS Rectangular Plates, Mode Shape, Nonlinear Free Vibration, Laminate Theory

\section{Introduction}

The geometrically nonlinear vibration of structures is of continuing interest, due to the tendency to build more reliable structures, with high strength, high stiffness, and low weight such as composites. Such new materials have a more accentuated nonlinear behavior [1]-[6]. It is then necessary to develop new design concepts, taking into account the nonlinear behavior induced by large vibration amplitudes, which may occur for example in severe environments. The large displacement amplitudes induce geometrical nonlinearity that is mainly caused by the development of in-plane membrane stresses. In such cases, one of the basic assumptions of the linear vibra- 
tion theory, i.e. small displacement amplitudes compared to the plate thickness is violated. Therefore, it is of crucial theoretical and practical interest, to develop new approaches which take into account the membrane stress effect, neglected in the classical treatment of plate vibrations. Even though the vibration of plates overall has interested researchers for a long time, the exact linear solutions are known only for the six cases having two opposite edges simply supported corresponding to a square plate or a rectangular plate [7] [8]. Also, as has been mentioned in the study made by Leissa in 1973 [7], it was pointed out that until 1954, when Warburton derived his formulae based on a single-term representation of the deflection shapes for the natural frequencies of plates with various boundary conditions, no solution, even approximate, was known for six boundary condition cases. The general accuracy of Warburton's formulae is discussed in references [7] [8].

A great deal of studies and a wide program of experimental work carried out by White and his co-workers [9][18] has been developed in order to understand the dynamic behavior of homogeneous and CFRP beams and plates. In Chia's book [19], an extensive information is given on the nonlinear analysis of plates, with presentation of a variety of geometrically nonlinear static and dynamic problems. Also, a survey was presented of the literature on the geometrical nonlinear analysis of laminated composite elastic plates in reference [20]. In Sathyamoorthy's work [21], a review was presented which deals with analytical, numerical and experimental methods used in the geometrically nonlinear dynamic analysis of plates.

In recent works carried out by F. Alijani and M. Amabili [22] [23] in 2013, nonlinear vibrations of completely free laminated and sandwich rectangular plates are investigated using a multi-modal energy approach based on Lagrange equations and by using classical and higher-order shear deformation theories [24] with von Karman type nonlinearities [25].

In several engineering applications, large vibration amplitudes of plate-type structures are encountered especially in the aerospace sector. The plates are assumed to be whether fully or partially free, simply supported, or clamped. The clamped boundary conditions assume that both displacements and rotations are prevented. In exchange, the simply supported boundary conditions assume that displacements are allowed, but rotations are not. In practice, it is extremely hard to achieve both cases [26], because the real plate boundaries are neither completely clamped nor simply supported. So, in most cases, the real boundary conditions are a combination of clamped, simply supported, or free conditions. As a real illustrative example of the combination of the boundary conditions, aircraft wing panels may be mentioned [27].

The purpose of this paper is to apply the theoretical model developed in references [1]-[3] in order to analyze the geometrically nonlinear free dynamic response of C-C-SS-SS rectangular CFRP symmetrically laminated plates so as to investigate the effect of nonlinearity on the nonlinear resonance frequencies, the nonlinear fundamental mode shape and associated bending stress patterns at large vibration amplitudes. Various values of the plate aspect ratio and the amplitude of vibration will be considered, and useful numerical data will be provided.

\section{General Formulation of the Geometrically Nonlinear Free Vibration of C-C-SS-SS Symmetrically Laminated Rectangular Composite Plates}

\subsection{Constitutive Equation at Large Deflections}

Consider the transverse vibration $W$ of the plate of dimensions $a, b$ and $H$ shown in Figure 1 with a coordinate system taken such that the $x y$ plane coincides with the mid-plane of the plate.

The strain-displacement relationships for large deflections, considering the classical plate laminated theory [28], are given by the expressions taken from reference [29] which assume that (a) the plate is thin (the thickness $\mathrm{H}$ is much smaller than the typical plate dimension, $\mathrm{H}<<\mathrm{a}, \mathrm{b}$ ), (b) the magnitude of the transverse deflection

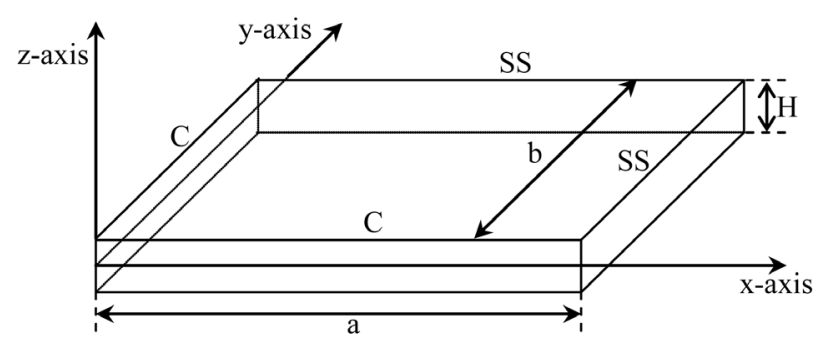

Figure 1. The plate notation. 
$W$ is of the same order as the thickness of the plate, and (c) the in-plane displacements $\mathrm{U}$ and $\mathrm{V}$ are linear functions of the $z$-coordinate:

$$
\{\varepsilon\}=\left\{\varepsilon^{0}\right\}+z\{k\}+\left\{\lambda^{0}\right\} .
$$

where $\left\{\varepsilon^{0}\right\},\{k\}$ and $\left\{\lambda^{0}\right\}$ are given by [1]-[5]:

$$
\left\{\varepsilon^{0}\right\}=\left\{\begin{array}{c}
\varepsilon_{x}^{0} \\
\varepsilon_{y}^{0} \\
\varepsilon_{z}^{0}
\end{array}\right\}=\left\{\begin{array}{c}
\frac{\partial U}{\partial x} \\
\frac{\partial V}{\partial y} \\
\frac{\partial U}{\partial y}+\frac{\partial V}{\partial x}
\end{array}\right\}, \quad\{k\}=\left\{\begin{array}{c}
k_{x} \\
k_{y} \\
k_{x y}
\end{array}\right\}=\left\{\begin{array}{c}
-\frac{\partial^{2} W}{\partial x^{2}} \\
-\frac{\partial^{2} W}{\partial y^{2}} \\
\frac{\partial^{2} W}{\partial x y}
\end{array}\right\}, \quad \text { and }\{\lambda\}=\left\{\begin{array}{l}
\lambda_{x}^{0} \\
\lambda_{y}^{0} \\
\lambda_{z}^{0}
\end{array}\right\}=\left\{\begin{array}{l}
\frac{1}{2}\left(\frac{\partial W}{\partial x}\right)^{2} \\
\frac{1}{2}\left(\frac{\partial W}{\partial y}\right)^{2} \\
\frac{\partial W}{\partial x} \frac{\partial W}{\partial y}
\end{array}\right\}
$$

where $U, V$, and $W$ are the displacements of the plate mid-plane, in the $x, y$ and $z$ directions respectively. In the development of the nonlinear energy expression, the transverse displacement $W$ of the plate mid-plane has been taken into consideration while the in-plane displacements $U$ and $V$ have been neglected. Therefore, the strain energy $(5,6)$ of an elastic solid is written in Cartesian coordinates as follows [1]-[5]:

$$
\begin{aligned}
& V_{b}= \\
& \frac{1}{2} \iint\left[D_{11}\left(\frac{\partial^{2} W}{\partial x^{2}}\right)^{2}+2 D_{12} \frac{\partial^{2} W}{\partial x^{2}} \frac{\partial^{2} W}{\partial y^{2}}+D_{22}\left(\frac{\partial^{2} W}{\partial y^{2}}\right)^{2}+4 D_{16} \frac{\partial^{2} W}{\partial x^{2}} \frac{\partial^{2} W}{\partial x y}+4 D_{26} \frac{\partial^{2} W}{\partial x^{2}} \frac{\partial^{2} W}{\partial x y}+4 D_{66}\left(\frac{\partial^{2} W}{\partial x y}\right)^{2}\right] \mathrm{d} x \mathrm{~d} y \\
& V_{a}=\frac{1}{2} \iint\left[\frac{A_{11}}{4}\left(\frac{\partial W}{\partial x}\right)^{4}+\frac{A_{22}}{4}\left(\frac{\partial W}{\partial y}\right)^{4}+\left(\frac{A_{22}}{2}+A_{66}\right)\left(\frac{\partial W}{\partial y}\right)^{2}\left(\frac{\partial W}{\partial x}\right)^{2} A_{16}\left(\frac{\partial W}{\partial x}\right)^{3} \frac{\partial W}{\partial y}+A_{26}\left(\frac{\partial W}{\partial y}\right)^{3} \frac{\partial W}{\partial x}\right] \mathrm{d} x \mathrm{~d} y
\end{aligned}
$$

The kinetic energy of the plate may be written as [1]-[5]:

$$
T=\frac{1}{2} \rho H \iint\left(\frac{\partial W}{\partial t}\right)^{2} \mathrm{~d} x \mathrm{~d} y
$$

In which the in-plane and rotary inertia terms are neglected.

\subsection{Numerical Model for the Nonlinear Mode Shapes and Resonance Frequencies of C-C-SS-SS Rectangular CFRP Symmetrically Laminated Plates}

The transverse displacement function $W$ may be written as in references [29] [30] in the form of a double series as follows:

$$
W(x, y, t)=w(x, y) \sin \omega t=\sum_{i=1}^{N} \sum_{j=1}^{N} a_{i j} w_{i j}(x, y) \sin \omega t
$$

where $i j$ is the contribution coefficient of the function obtained as product of the $i^{\text {th }}$ clamped simply-supported beam mode shape in the $x$-direction, with the $j^{\text {th }}$ clamped simply-supported beam mode shape in the $y$-direction for the case of C-C-SS-SS rectangular plates, and vice versa.

The discretization of the strain and kinetic energy expressions (5)-(7) can be carried out leading to [1]-[5]:

$$
V_{b}=\frac{1}{2} a_{i} a_{j} k_{i j} \sin ^{2} \omega t, \quad V_{a}=\frac{1}{2} a_{i} a_{j} b_{i j k} \sin ^{4} \omega t \quad \text { and } \quad T=\frac{1}{2} a_{i} a_{j} \omega^{2} m_{i j} \cos ^{2} \omega t
$$

where $m_{i j}, k_{i j}$, and $b_{i j k l}$ are respectively the mass tensor, the rigidity tensor and the geometrical nonlinearity tensor. These tensors are related to the corresponding nondimensional ones by:

$$
m_{i j}=\rho H^{5} a b m_{i j}^{*}, \quad k_{i j}=\frac{a H^{5} E}{b^{3}} k_{i j}^{*} \text { and } \quad b_{i j k l}=\frac{a H^{5} E}{b^{3}} b_{i j k l}^{*}
$$

where the nondimensional tensors $m_{i j}^{*}, k_{i j}^{*}$, and $b_{i j k l}^{*}$ have the below form: 


$$
\begin{aligned}
& m_{i j}^{*}=\iint w_{i}^{*} w_{j}^{*} \mathrm{~d} x^{*} \mathrm{~d} y^{*} \\
& k_{i j}^{*} \iint\left[D_{11}^{*} \alpha^{4}\left(\frac{\partial^{2} w_{i}^{*}}{\partial x^{* 2}} \frac{\partial^{2} w_{j}^{*}}{\partial x^{* 2}}\right)+D_{12}^{*} \alpha^{2}\left(\frac{\partial^{2} w_{i}^{*}}{\partial x^{* 2}} \frac{\partial^{2} w_{j}^{*}}{\partial y^{* 2}}+\frac{\partial^{2} w_{i}^{*}}{\partial y^{* 2}} \frac{\partial^{2} w_{j}^{*}}{\partial x^{* 2}}\right)+D_{22}^{*}\left(\frac{\partial^{2} w_{i}^{*}}{\partial y^{* 2}} \frac{\partial^{2} W_{j}^{*}}{\partial y^{* 2}}\right)\right. \\
&+2 D_{16}^{*} \alpha^{3}\left(\frac{\partial^{2} w_{i}^{*}}{\partial x^{* 2}} \frac{\partial^{2} w_{j}^{*}}{\partial x^{*} y^{*}}+\frac{\partial^{2} w_{i}^{*}}{\partial x^{*} y^{*}} \frac{\partial^{2} w_{j}^{*}}{\partial x^{* 2}}\right)+2 D_{26}^{*} \alpha\left(\frac{\partial^{2} w_{i}^{*}}{\partial y^{* 2}} \frac{\partial^{2} w_{j}^{*}}{\partial x^{*} y^{*}}+\frac{\partial^{2} w_{i}^{*}}{\partial x^{*} y^{*}} \frac{\partial^{2} w_{j}^{*}}{\partial y^{* 2}}\right) \\
&\left.+4 D_{66}^{*} \alpha^{2}\left(\frac{\partial^{2} w_{i}^{*}}{\partial x^{*} y^{*}} \frac{\partial^{2} w_{j}^{*}}{\partial x^{*} y^{*}}\right)\right] \mathrm{d} x^{*} \mathrm{~d} y^{*} . \\
& b_{i j k l}^{*}=\iint\left[\frac{A_{11}^{*}}{4} \alpha^{4}\left(\frac{\partial w_{i}^{*}}{\partial x^{*}} \frac{\partial w_{j}^{*}}{\partial x^{*}} \frac{\partial w_{k}^{*}}{\partial x^{*}} \frac{\partial w_{l}^{*}}{\partial x^{*}}\right)+\frac{A_{22}^{*}}{4}\left(\frac{\partial w_{i}^{*}}{\partial y^{*}} \frac{\partial w_{j}^{*}}{\partial y^{*}} \frac{\partial w_{k}^{*}}{\partial y^{*}} \frac{\partial w_{l}^{*}}{\partial y^{*}}\right)\right. \\
&+\left(\frac{A_{12}^{*}}{4}+\frac{A_{66}^{*}}{2}\right) \alpha^{2}\left\{\left(\frac{\partial w_{i}^{*}}{\partial y^{*}} \frac{\partial w_{j}^{*}}{\partial y^{*}} \frac{\partial w_{k}^{*}}{\partial x^{*}} \frac{\partial w_{l}^{*}}{\partial x^{*}}\right)+\left(\frac{\partial w_{i}^{*}}{\partial x^{*}} \frac{\partial w_{j}^{*}}{\partial x^{*}} \frac{\partial w_{k}^{*}}{\partial y^{*}} \frac{\partial w_{l}^{*}}{\partial y^{*}}\right)\right\} \\
&+\frac{A_{16}^{*}}{2} \alpha^{3}\left\{\left(\frac{\partial w_{i}^{*}}{\partial x^{*}} \frac{\partial w_{j}^{*}}{\partial x^{*}} \frac{\partial w_{k}^{*}}{\partial x^{*}} \frac{\partial w_{l}^{*}}{\partial y^{*}}\right)+\left(\frac{\partial w_{i}^{*}}{\partial x^{*}} \frac{\partial w_{j}^{*}}{\partial x^{*}} \frac{\partial w_{k}^{*}}{\partial y^{*}} \frac{\partial w_{l}^{*}}{\partial x^{*}}\right)\right\} \\
&+\left.\frac{A_{26}^{*}}{2} \alpha\left\{\left(\frac{\partial w_{i}^{*}}{\partial x^{*}} \frac{\partial w_{j}^{*}}{\partial y^{*}} \frac{\partial w_{k}^{*}}{\partial y^{*}} \frac{\partial w_{l}^{*}}{\partial y^{*}}\right)+\left(\frac{\partial w_{i}^{*}}{\partial y^{*}} \frac{\partial w_{j}^{*}}{\partial x^{*}} \frac{\partial w_{k}^{*}}{\partial y^{*}} \frac{\partial w_{l}^{*}}{\partial y^{*}}\right)\right\}\right] \mathrm{d} x \mathrm{~d} y .
\end{aligned}
$$

Applying Hamilton's principle to the vibration problem gives:

$$
3 a_{i} a_{j} a_{k} b_{i j k r}^{*}+2 a_{i} k_{i r}^{*}-2 \omega^{* 2} a_{i} m_{i r}^{*}=0, \quad r=1, \cdots, n
$$

In matrix form, the above expression (18) may be rewritten as:

$$
3\left[B^{*}(A)\right]\{A\}+2\left[K^{*}\right]\{A\}-2 \omega^{* 2}\left[M^{*}\right]\{A\}=\{0\}
$$

where $\omega^{*}$ is the nondimensional nonlinear frequency parameter, the expression of which can be obtained by pre-multiplying Equation (18) by $[A]^{\mathrm{T}}$ from the left-hand side, which leads to the following equation:

$$
\omega^{* 2}=\frac{a_{i} a_{j} k_{i j}^{*}+\frac{3}{2} a_{i} a_{j} a_{k} a_{l} b_{i j k l}^{*}}{a_{i} a_{j} m_{i j}^{*}}
$$

The set of nonlinear algebraic Equations (20), in which the parameters $b_{i j k l}^{*}, k_{i j}^{*}$ and $m_{i j}^{*}$ were computed numerically by using Simpson's rule, has been solved numerically by using the Harwell library routine NS01A. This routine is based on a hybrid method combining the steepest descent and Newton's methods, to obtain the numerical results presented for the first nonlinear mode of a C-C-SS-SS anisotropic rectangular plate.

\section{Applications to C-C-SS-SS Rectangular Laminated CFRP Composite Panels}

Table 1, given below, shows the geometrical and material characteristics of the CFRP rectangular composite plates examined in the present work, taken from Reference [31].

Table 1. Geometric and material properties of the rectangular plate.

\begin{tabular}{ccccc}
\hline Number of layers & Orientation of principal axes & $a(\mathrm{~mm})$ & $b(\mathrm{~mm})$ & $H(\mathrm{~mm})$ \\
\hline 8 & $(90,45,-45,0)$ sym & 480 & 320 & 1 \\
\hline$E_{x}(\mathrm{Gpa})$ & $E_{y}(\mathrm{Gpa})$ & $G_{x y}(\mathrm{Gpa})$ & $v_{x y}$ & $\rho\left(\mathrm{kg} / \mathrm{m}^{3}\right)$ \\
\hline 120.5 & 9.63 & 3.58 & 0.32 & 1540 \\
\hline
\end{tabular}


In the present work, the set of admissible functions concerning C-C-SS-SS composite rectangular plates are obtained as products of linear clamped simply-supported beam mode shapes in the $x$ - and $y$-directions. Such beam functions have been used previously to build plate functions and shown to be appropriate in both linear and nonlinear vibration studies [2] [5].

The beam functions, whose analytical expressions are given in Appendix, used in the present work lead to plate-functions which satisfy all of the C-C-SS-SS theoretical boundary conditions, i.e. zero displacement along the four edges, zero slope along the two clamped edges, and zero moment with respect to $\mathrm{x}$ and $\mathrm{y}$ along the two simply supported edges.

\subsection{Linear Analysis}

In order to verify the accuracy of the results obtained in the present work corresponding to the C-C-SS-SS rectangular plate, we will compare the solution of Equation (21), that is considered as an eigen problem which will be solved by using MATLAB software, with the previous published results.

$$
a_{j} k_{i r}^{*}=a_{i} \omega^{* 2} m_{i r}^{*}, \quad r=1, \cdots, n
$$

The calculation was made by using 36 basic functions obtained as products of the first six clamped simplysupported beam functions, leading to square mass and rigidity matrices of dimension 25 .

In Table 2, the nonlinear frequency parameters obtained from the nonlinear analysis at very small vibration amplitudes $\left(a_{11}=0.001\right.$ and 0.15$)$ corresponding to various values of the plate aspect ratio, are compared with results obtained from linear analysis. Consequently, the results show the convergence of the nonlinear model to the linear approach at very small vibration amplitudes.

\subsection{Nonlinear Analysis}

Table 3 gives a summary of the first nonlinear mode shape of C-C-SS-SS rectangular plate results, corresponding to $\alpha=0.667$ for $a_{11}=0.001$ and 0.15 , which are calculated here using 25 basic functions.

The qualitative comparison that is done in Figure 2 for the nonlinear frequency parameters of the first

Table 2. Comparison of nondimensional frequency parameters.

\begin{tabular}{ccccccc}
\hline & \multicolumn{5}{c}{ Aspect ratio $\alpha$} \\
\cline { 3 - 6 } & & 0.4 & 0.5 & 0.667 & 1.0 & 1.5 \\
\hline$\omega_{n l}^{*} \quad\left(a_{11}=0.001\right)$ & 9.121334 & 11.462156 & 17.89945 & 46.446766 & 166.25356 \\
$\omega_{n l}^{*} \quad\left(a_{11}=0.15\right)$ & 9.8864237 & 12.339166 & 19.123762 & 49.411693 & 176.96215 \\
\hline
\end{tabular}

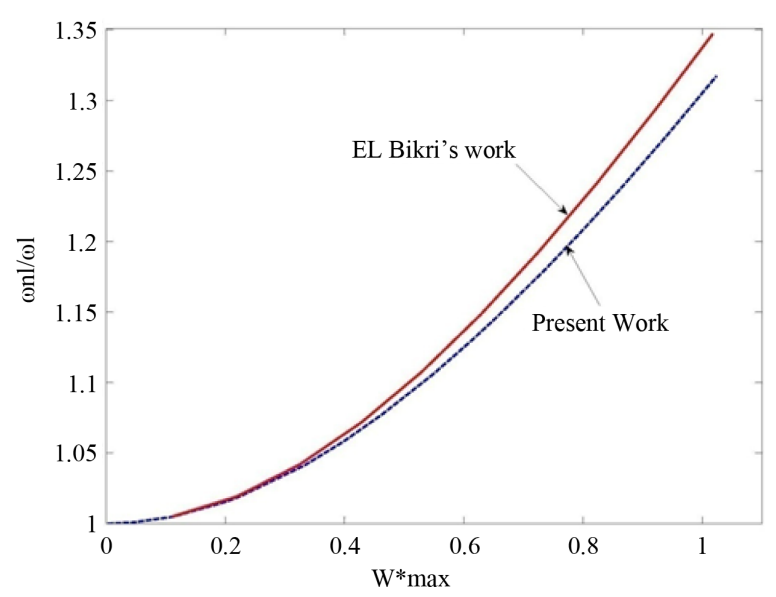

Figure 2. Comparison of the nonlinear frequency parameters of the first nonlinear mode of C-C-SS-SS rectangular plate. -: present work, ---: value taken from [31] corresponding to $\alpha=0.4$. 
Table 3. Comparison of nondimensional frequency parameters.

\begin{tabular}{|c|c|c|c|}
\hline & & $W_{\max }=0.11173319 \mathrm{E}-01$ & $W_{\max }=0.26809814$ \\
\hline & (a) $\omega_{1}^{*}=17.89957$ & (b) $\omega_{n l}^{*}=17.89945$ & (c) $\omega_{n l}^{*}=19.123762$ \\
\hline$a_{11}$ & 1 & 0.001 & 0.15 \\
\hline$a_{12}$ & 0.034640933 & $0.34693649 \mathrm{E}-04$ & $0.71160884 \mathrm{E}-02$ \\
\hline$a_{13}$ & 0.007849452 & $0.78612035 \mathrm{E}-05$ & $0.10368977 \mathrm{E}-02$ \\
\hline$a_{14}$ & 0.002492575 & $0.24964054 \mathrm{E}-05$ & $0.61552283 \mathrm{E}-03$ \\
\hline$a_{15}$ & 0.000990265 & $0.99177280 \mathrm{E}-06$ & $0.21810887 \mathrm{E}-03$ \\
\hline$a_{21}$ & 0.040354981 & $0.40415664 \mathrm{E}-04$ & $0.62294442 \mathrm{E}-02$ \\
\hline$a_{22}$ & -0.001785123 & $-0.17877778 E-05$ & $-0.14783568 \mathrm{E}-03$ \\
\hline$a_{23}$ & -0.001032162 & $-0.10337164 \mathrm{E}-05$ & $-0.14807638 \mathrm{E}-03$ \\
\hline$a_{24}$ & -0.000468162 & $-0.46886538 \mathrm{E}-06$ & $-0.63046742 \mathrm{E}-04$ \\
\hline$a_{25}$ & -0.00021805 & $-0.21837845 \mathrm{E}-06$ & $-0.32070459 \mathrm{E}-04$ \\
\hline$a_{31}$ & 0.009393579 & $0.94078473 \mathrm{E}-05$ & $0.18552141 \mathrm{E}-02$ \\
\hline$a_{32}$ & -0.001170972 & $-0.11727421 \mathrm{E}-05$ & $-0.18827547 \mathrm{E}-03$ \\
\hline$a_{33}$ & -0.000763724 & $-0.76482717 \mathrm{E}-06$ & $0.33978506 \mathrm{E}-04$ \\
\hline$a_{34}$ & -0.000396506 & $-0.39711893 \mathrm{E}-06$ & $-0.10327654 \mathrm{E}-03$ \\
\hline$a_{35}$ & -0.000203788 & $-0.20409761 \mathrm{E}-06$ & $-0.44565495 \mathrm{E}-04$ \\
\hline$a_{41}$ & 0.003032144 & $0.30366964 \mathrm{E}-05$ & $0.42418279 \mathrm{E}-03$ \\
\hline$a_{42}$ & -0.000565483 & $-0.56632875 \mathrm{E}-06$ & $-0.67252538 \mathrm{E}-04$ \\
\hline$a_{43}$ & -0.000425984 & $-0.42663248 E-06$ & $-0.87193658 \mathrm{E}-04$ \\
\hline$a_{44}$ & -0.000250132 & $-0.25050635 \mathrm{E}-06$ & $-0.31356367 \mathrm{E}-04$ \\
\hline$a_{45}$ & -0.000140975 & $-0.14118626 \mathrm{E}-06$ & $-0.19236005 E-04$ \\
\hline$a_{51}$ & 0.001214007 & $0.12158334 \mathrm{E}-05$ & $0.18055087 \mathrm{E}-03$ \\
\hline$a_{52}$ & -0.000273669 & $-0.27407930 \mathrm{E}-06$ & $-0.34861000 \mathrm{E}-04$ \\
\hline$a_{53}$ & -0.000229392 & $-0.22973835 E-06$ & $-0.36839827 \mathrm{E}-04$ \\
\hline$a_{54}$ & -0.000148152 & $-0.14837451 \mathrm{E}-06$ & $-0.21774339 \mathrm{E}-04$ \\
\hline$a_{55}$ & $-9.01 \mathrm{E}-05$ & $-0.90258064 \mathrm{E}-07$ & $-0.13305140 \mathrm{E}-04$ \\
\hline
\end{tabular}

(a) Linear results calculated here; (b) present results obtained from nonlinear analysis for $a_{11}=0.001$; (c) present results obtained from nonlinear analysis for $a_{11}=0.15$.

nonlinear mode, between the results obtained here and those obtained in Reference [31] for an isotropic square plate with similar boundary conditions showed that the curve (continuous line) obtained in Bikri's work increases more than the curve (dashed) corresponding to the present work. On the other hand, the comparison done with the work of B. Harras et al. in Figure 3 shows that the fully clamped anisotropic rectangular plate exhibits less nonlinearity than that examined in the present work.

In Figure 4 are plotted the nonlinear frequency versus the maximum nondimensional amplitude for the first non-linear mode shape of C-C-SS-SS rectangular plate for various values of the plate aspect ratio. All curves are similar to those mentioned in References [5] [31].

The curves in Figure 5 and Figure 6, obtained via the present model, are plotted respectively for the values of the maximum nondimensional amplitudes $W_{\max }^{*}(\alpha=1.0)=0.223 \mathrm{E}-02,1.360,2.560$, and 


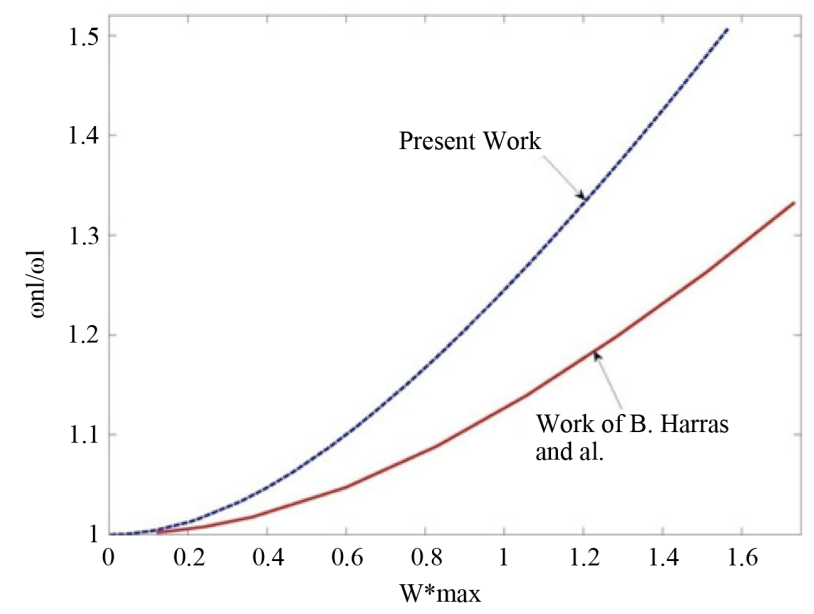

Figure 3. Comparison of the nonlinear frequency parameters of the first nonlinear mode of anisotropic C-C-SS-SS rectangular plate (present work) with anisotropic fully clamped rectangular plate (work of B. Harras et al. values taken from [5]) corresponding to $\alpha=0.667$.

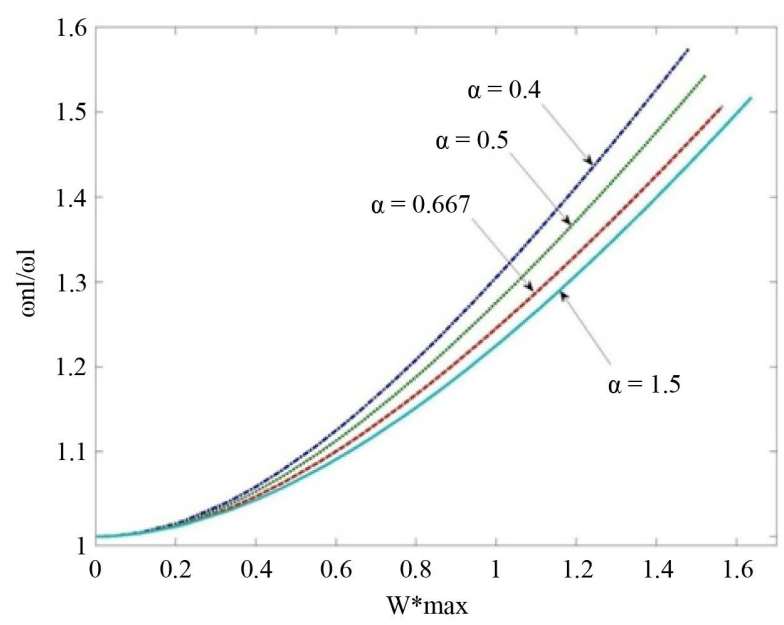

Figure 4. Comparison of the change frequency of the first mode for $\alpha=0.4,0.5,0.667$, and 1.5 .

$W_{\max }^{*}(\alpha=1.5)=0.222 \mathrm{E}-02,1.386,2.604$, along the $y$-direction of the nonlinear fundamental mode shape of a rectangular plate ( $\alpha=1.0$ and 0.5 ) corresponding to $X_{\max }^{*}$. They show the amplitude dependence of the nonlinear mode shape and an increase of curvatures near to the clamped edges. On the other hand, no changes are noticed close to the simply supported ones, thereby, we suppose that the flexural stresses will increase nonlinearly near to the clamped edges accompanying increase of the vibration amplitudes.

Figure 7 and Figure 8 represent the nondimensional flexural stress distributions associated to the first non linear mode shape of a C-C-SS-SS rectangular plate, which show the effect of large vibration amplitudes along the $x$ and $y$ directions, corresponding to $Y^{*}=0.5$ and $X^{*}=0.25$ for $\alpha=0.667$. Besides, all curves show that the flexural stress is equal to zero close to the edge where the rectangular plate is simply supported, but on the other side the flexural stress exhibit a higher increase which has been proved in the linear vibration approach.

\section{Conclusions}

The nonlinear free vibrations of C-C-SS-SS rectangular symmetrically laminated plates are studied in this paper 


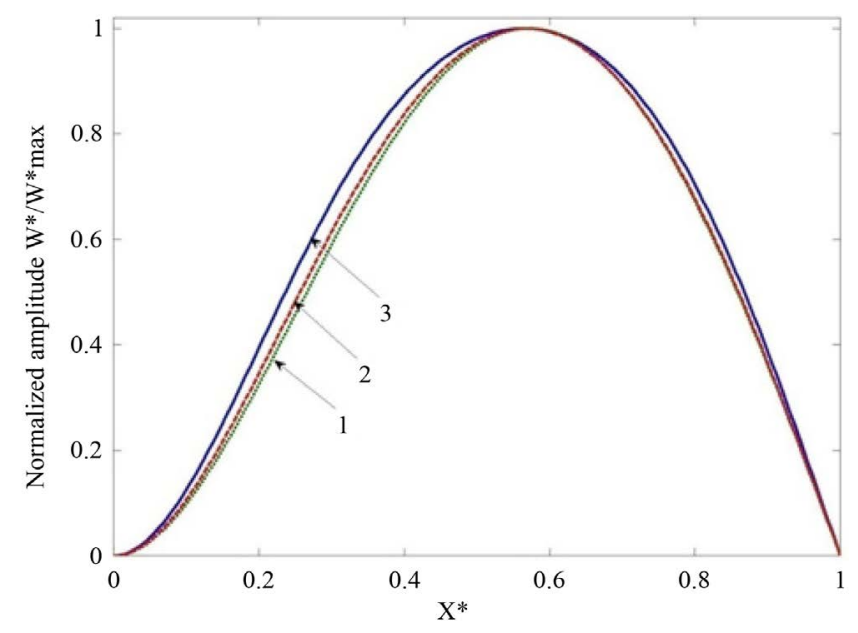

Figure 5. Normalized first nonlinear mode of a C-C-SS-SS rectangular plate corresponding to $X_{\max }^{*}$ and $\alpha=1.0$. Curve 1, lowest amplitude; Curve 3, highest amplitude.

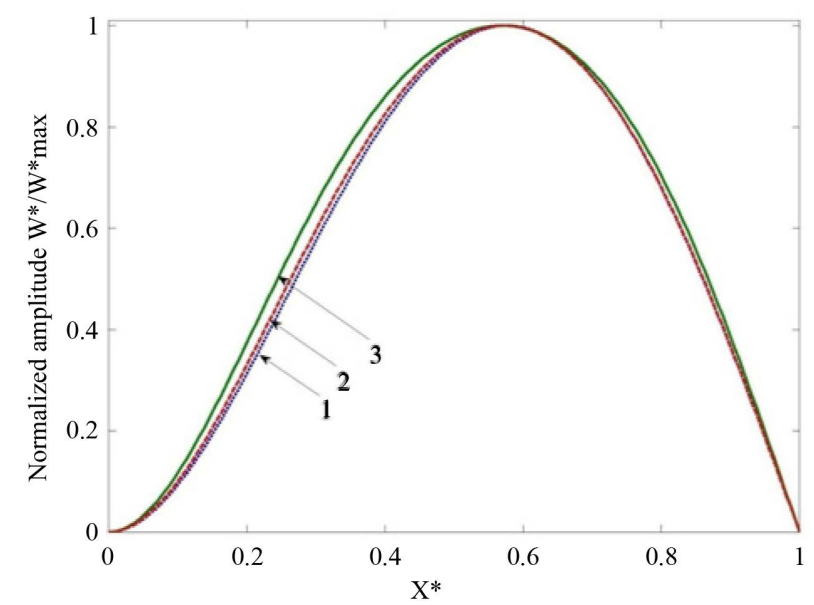

Figure 6. Normalized first nonlinear mode of a C-C-SS-SS rectangular plate for $X_{\max }^{*}$ and $\alpha=1.5$. Curve 1, lowest amplitude; Curve 3, highest amplitude.

using a theoretical model developed previously in References [4]-[6] for geometrically nonlinear free vibrations of thin elastic structures. The objective was to determine the effects of large vibration amplitudes on the first nonlinear mode shape, the fundamental natural frequency, and the associated flexural stress distribution. The model, based on Hamilton's principle, reduces the nonlinear free vibration problem to solution of a set of nonlinear algebraic equations involving the classical rigidity and mass tensors and a fourth order tensor due to the geometrical nonlinearity.

The study of the first nonlinear mode shape for the CFRP plates considered has shown that the curvature near the edge increases very rapidly with increase of the vibration amplitude. In addition, the mode shape close to the center of the plate becomes flatter when the amplitude increases. It was also noticed that the deformation of the mode shape, for a given value of the normalized amplitude of vibration, increases as the aspect ratio $\alpha$ increases. The nondimensional bending stress distribution associated with the CFRP rectangular plate first nonlinear mode shows an increase with increasing $\mathrm{a}_{11}$ which is much higher than that obtained for CFRP plates of identical aspect ratio. As a consequence of the deformation of the mode shape, a higher rate of increase was noticed in the induced bending stresses in a region close to the clamped edges. Furthermore, the nondimensional bending stress distribution associated with the CFRP rectangular plate first nonlinear mode for different amplitudes- 


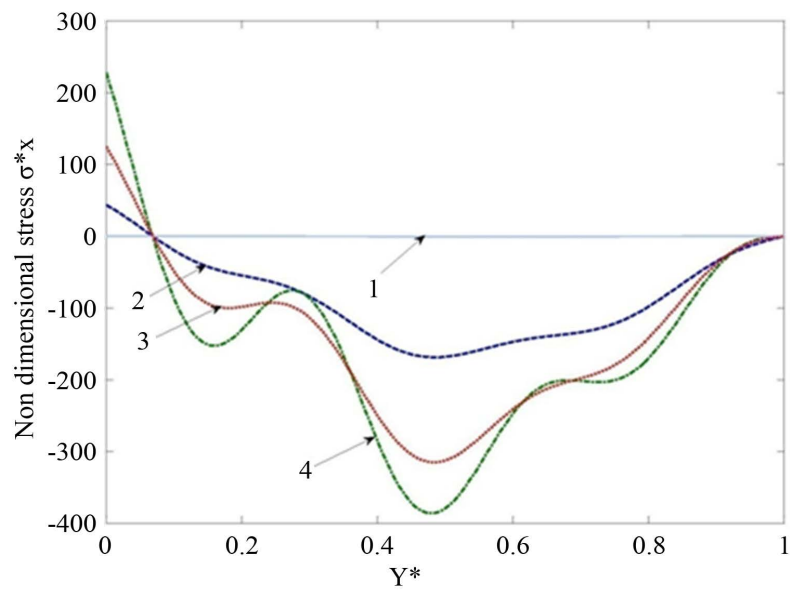

Figure 7. Nondimensional bending stress distribution associated with C-C-SS-SS rectangular plate first nonlinear mode along $Y^{*}=0.5$ for $\alpha=0.667$. Curve 1 , lowest amplitude; Curve 4 highest amplitude.

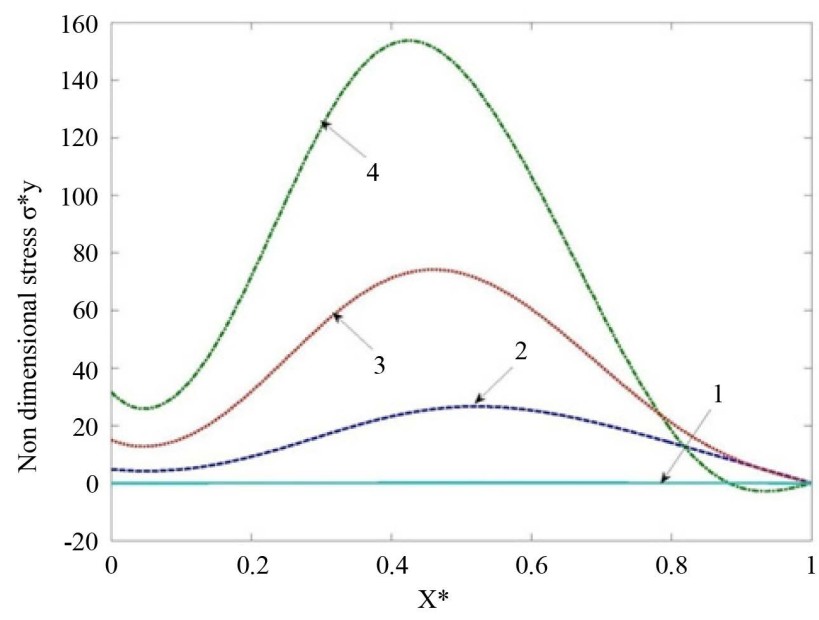

Figure 8. Nondimensional bending stress distribution associated with C-C-SS-SS rectangular plate first nonlinear mode along $X^{*}=0.25$ for $\alpha=0.667$. Curve 1, lowest amplitude; Curve 4 highest amplitude.

of vibration show a nonsymmetry along the length of the section considered because of the influence of the fiber orientation. It is worth noting here that further investigations are needed in order to check the distribution of the nonlinear bending stresses obtained at very high amplitudes of vibration.

At last, this present work enabled us to find out how the thin elastic structures behave at the large vibration amplitude by plotting different nonlinear dynamic characteristics. In addition, the qualitative comparison done with the results of an isotropic rectangular plate with similar boundary conditions obtained in reference [31], and whith an anisotropic rectangular plate examined in reference [5] showed good and satisfactory results.

\section{References}

[1] Benamar, R., Bennouna, M.M.K. and White, R.G. (1991) The Effects of Large Vibration Amplitudes on the Fundamental Mode Shape of Thin Elastic Structures. Part I: Simply Supported and Clamped Clamped Beams. Journal of Sound and Vibration, 149, 179-195. http://dx.doi.org/10.1016/0022-460X(91)90630-3

[2] Benamar, R., Bennouna, M.M.K. and White, R.G. (1993) The Effects of Large Vibration Amplitudes on the Fundamental Mode Shape of Thin Elastic Structures. Part II: Fully Clamped Rectangular Isotropic Plates. Journal of Sound 
and Vibration, 164, 295-316. http://dx.doi.org/10.1006/jsvi.1993.1215

[3] Benamar, R., Bennouna, M.M.K. and White, R.G. (1990) The Effects of Large Vibration Amplitudes on the Fundamental Mode Shape of a Fully Clamped, Symmetrically Laminated Rectangular Plate. Proceedings of the 4th International Conference on Recent Advances in Structural Dynamics, Southampton.

[4] Harras, B., Benamar, R. and White, R.G. (2002) Experimental and Theoretical Investigation of the Linear and NonLinear Dynamic Behavior of a Glare 3 Hybrid Composite Panel. Journal of Sound and Vibration, 2, 281-315. http://dx.doi.org/10.1006/jsvi.2001.3962

[5] Harras, B., Benamar, R. and White, R.G. (2002) Geometrically Non-Linear Free Vibration of Fully Clamped Symmetrically Laminated Rectangular Composite Plates. Journal of Sound and Vibration, 4, 579-619. http://dx.doi.org/10.1006/jsvi.2001.3713

[6] Harras, B., Benamar, R. and White, R.G. (2002) Investigation of Non-Linear Free Vibrations of Fully Clamped Symmetrically Laminated Carbon-Fibre-Treinforced PEEK (AS4/APC2) Rectangular Composite Panels. Composite Science and Technology, 62, 719-727. http://dx.doi.org/10.1016/S0266-3538(01)00133-6

[7] Leissa, A.W. (1973) Free Vibrations of Rectangular Plate. Journal of Sound and Vibration, 31, 257-293. http://dx.doi.org/10.1016/S0022-460X(73)80371-2

[8] Leissa, A.W. (1969) Vibration of Plates. NASA-SP-160. US Government Printing Office, Washington DC.

[9] White, R.G. (1978) A Comparison of Some Statistical Properties of the Responses of Aluminum and CFRP Plates to Acoustic Excitation. Composites, 9, 251-258. http://dx.doi.org/10.1016/0010-4361(78)90178-7

[10] Wolfe, H. (1995) An Experimental Investigation of Non-Linear Behaviour of Beams and Plates Excited to High Levels of Dynamic Response. Ph.D. Thesis, University of Southampton, Southampton.

[11] White, R.G. (1988) The Acoustic Excitation and Fatigue of Composite Plates. Proceedings of the 29th AIAA/ASME Structures, Structural Dynamics and Materials Conference, Williamsburg, Paper 88-2242, 253-260.

[12] Bennouna, M.M.K. (1981) Non-Linear Behaviour of a Clamped-Clamped Beam with Consideration of Fatigue Life. Ph.D. Thesis, Institute of Sound and Vibration Research, Southampton.

[13] Benamar, R. (1990) Non-Linear Dynamic Behaviour of Fully Clamped Beams and Rectangular Isotropic and Laminated Plates. Ph.D. Thesis, Institute of Sound and Vibration Research, Southampton.

[14] White, R.G. (1971) Effects of Non-Linearity Due to Large Deflections in the Resonance Testing of Structures. Journal of Sound and Vibration, 16, 255-267. http://dx.doi.org/10.1016/0022-460X(71)90486-X

[15] White, R.G. (1975) Some Measurements of the Dynamic Mechanical Properties of Mixed, Carbon Fiber Reinforced Plastic Beams and Plates. Aeronautical Journal, 79, 318-325.

[16] White, R.G. and Abdin, E.M.Y. (1985) Dynamic Properties of Aligned Short Carbon Fiber-Reinforced Plastics in Flexure and Torsion. Composites, 16, 293-306. http://dx.doi.org/10.1016/0010-4361(85)90282-4

[17] White, R.G. and Mousley, R.F. (1987) Dynamic Response of CFRP Plates under the Action of Random Acoustic loading. Proceedings of the Fourth International Conference on Composite Structures, Paisley College of Technology, 1519-1535.

[18] Ng, C.F. and White, R.G. (1988) Dynamic Behaviour of Postbuckled Isotropic Plates under In-Plane Compression. Journal of Sound and Vibration, 120, 1-18. http://dx.doi.org/10.1016/0022-460X(88)90331-8

[19] Chia, C.Y. (1980) Nonlinear Analysis of Plates. McGraw-Hill, New York.

[20] Chia, C.Y. (1988) Geometrically Nonlinear Behavior of Composite Plates: A Review. Applied Mechanics Reviews, 41, 439-451. http://dx.doi.org/10.1115/1.3151873

[21] Sathyamoorthy, M. (1987) Nonlinear Vibration Analysis of Plates: A Review and Survey of Current Developments. Applied Mechanics Reviews, 40, 1553-1561. http://dx.doi.org/10.1115/1.3149544

[22] Alijani, F. and Amabili, M. (2013) Nonlinear Vibrations of Laminated and Sandwich Rectangular Plates with Free Edges. Part 1: Theory and Numerical Simulations. Composite Structures, 105, 422-436. http://dx.doi.org/10.1016/j.compstruct.2013.05.034

[23] Alijani, F., Amabili, M., Ferrari, G. and D’Alessandro, V. (2013) Nonlinear Vibrations of Laminated and Sandwich Rectangular Plates with Free Edges. Part 2: Experiments \& Comparisons. Composite Structures, 105, 437-445. http://dx.doi.org/10.1016/j.compstruct.2013.05.020

[24] Reddy, J.N. (1996) Mechanics of Laminated Composite Plates: Theory and Analysis. CRC Press, Boca Raton.

[25] Nayfeh, A.H. and Frank Pai, P. (2004) Linear and Nonlinear Structural Mechanics. John Wiley \& Sons, Inc., Hoboken. http://dx.doi.org/10.1002/9783527617562

[26] Abrate, S. and Schoeppner, G. (1997) Identification of Support Conditions for Composite Beams and Plates from Natural Frequencies. 29 International SAMPE (Society for the Advancement of Materials and Process Engineering) Tech- 
nical Conference, Orlando, 28 October-1 November, 725-732.

[27] Teh, C.E. (1989) Dynamic Behaviour and Acoustic Fatigue of Isotropic and Anisotropic Panels under Combined Acoustic Excitation and Static in Plane Compression. Ph.D. Thesis, Institute of Sound and Vibration Research, Southampton.

[28] Ashton, J.E. and Whitney, J.M. (1970) Theory of Laminated Plates. Technomic Publication, Stanford.

[29] Timoshenko, S. (1959) Theory of Plates and Shells. McGraw-Hill, New York, 416.

[30] Timoshenko, S., Weinsowsky-Krieger, S. and Jones, R.M. (1975) Mechanics of Composite Materials. International Student Edition, McGraw-Hill Kogakusha, Ltd., Tokyo, 51.

[31] El Bikri, K., Benamar, R. and Bennouna, M. (2003) Geometrically Non-Linear Free Vibrations of Clamped Simply Supported Rectangular Plates. Part I: The Effects of Large Vibration Amplitudes on the Fundamental Mode Shape. Journal of Sound and Vibration, 81, 2029-2043. 


\section{Nomenclature}

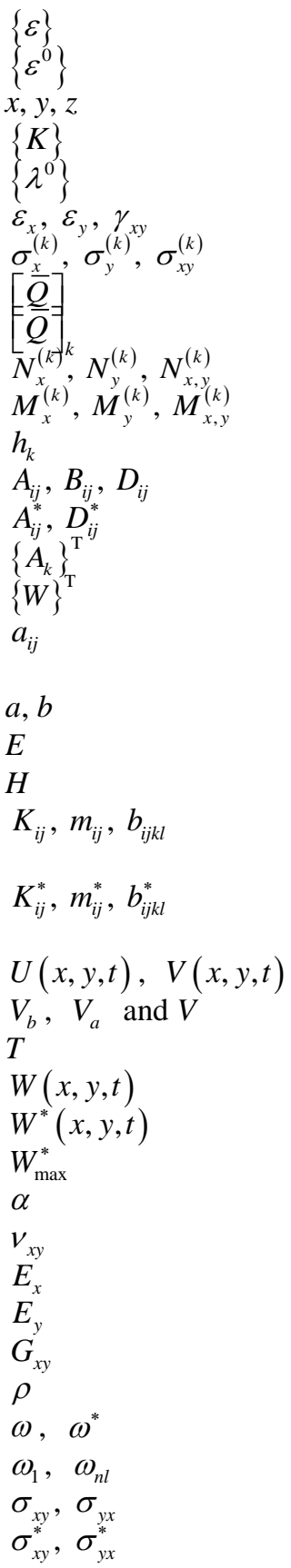

column matrix of total strains;

column matrix of strains due to the in-plane displacements $U, V, W$;

point co-ordinates;

column matrix of bending or twisting;

column matrix of strains induced by large displacements $W$;

strain tensor components;

stresses in the $k^{\text {th }}$ layer;

$6 \times 6$ matrix of transformed stiffness;

$6 \times 6$ matrix of transformed stiffness for the $k^{\text {th }}$ layer;

force resultant for the $k^{\text {th }}$ layer;

moment resultant for the $k^{\text {th }}$ layer;

distance from the mid-plane to the layer surface of the $k^{\text {th }}$ layer;

extensional, coupling and bending stiffness coefficients for the laminated plate;

nondimensional extensional and bending stiffness coefficients;

matrix of coefficients corresponding to the $k^{\text {th }}$ harmonic;

basic spatial functions matrix;

contribution coefficient of the plate deflection function obtained as a product of the $i^{\text {th }}$ and $j^{\text {th }}$ beam mode shapes in the $x$ and $y$ directions respectively;

length, width of the plate;

Young's modulus;

plate thickness;

general term of the rigidity tensor, the mass tensor and the nonlinearity tensor respectively;

general term of the nondimensional rigidity tensor, the mass tensor and the nonlinearity tensor respectively;

in-plane displacements at point $(x, y)$ of the plate;

bending, axial and total strain energy respectively;

kinetic energy;

transverse displacement at point $(x, y)$ of the plate midplane;

nondimensional transverse displacement at point $(x, y)$ of the plate midplane;

maximum of the nondimensional transverse displacement;

nondimensional parameter (plate aspect ratio) given by $\alpha=b / a$;

major Poisson's ratio;

longitudinal modulus of elasticity;

transverse modulus of elasticity;

shear modulus;

mass density per unit volume of the plate;

Frequency and nondimensional frequency parameter respectively;

linear frequency and nonlinear frequency respectively;

dimensional bending stresses;

nondimensional bending stresses.

\section{Appendix}

The clamped simply-supported beam functions $P_{i}^{*}(x)$ are defined as follows (Table 4 and Figure 9):

$$
P_{i}^{*}(x)=\left[\cos \left(\frac{\lambda_{i} x}{a}\right)-\cosh \left(\frac{\lambda_{i} x}{a}\right)\right]-\gamma_{i}\left[\sin \left(\frac{\lambda_{i} x}{a}\right)-\sinh \left(\frac{\lambda_{i} x}{a}\right)\right]
$$

where

$$
\gamma_{i}=\frac{\operatorname{ch}\left(\lambda_{i}\right)-\cos \left(\lambda_{i}\right)}{\operatorname{sh}\left(\lambda_{i}\right)-\sin \left(\lambda_{i}\right)}
$$


Table 4. The eigenvalue parameters for a C-C-SS-SS beam.

\begin{tabular}{cccc}
\hline$i$ & $\lambda_{i}$ & $i$ & $\lambda_{i}$ \\
\hline 1 & 3.926990817 & 9 & 29.059732046 \\
2 & 7.068583471 & 10 & 32.201324700 \\
3 & 10.210176124 & 11 & 35.342917353 \\
4 & 13.351768778 & 12 & 38.484510006 \\
5 & 16.493361431 & 13 & 41.626102660 \\
6 & 19.634954085 & 14 & 44.767695314 \\
7 & 22.776546739 & 15 & 47.909287967 \\
8 & 25.918139392 & 16 & 51.050880621 \\
\hline
\end{tabular}

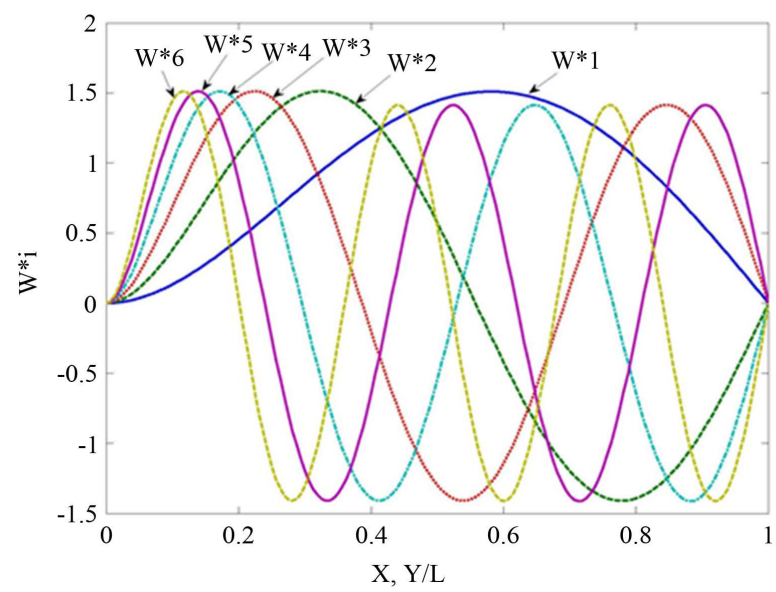

Figure 9. Clamped simply-supported beam functions for $i=1$,

\section{$2,3,4,5$, and 6 .}

In which $\lambda_{i}$ for $i=1,2, \cdots$ are the eigen value parameters for a clamped simply-supported beam. Besides the values of the parameters $\lambda_{i}$ were computed solving numerically the transcendental equation $\tanh \lambda_{i}-\tan \lambda_{i}=0$ by using Newton's method.

$$
w_{i}^{*}=\frac{1}{G} P_{\alpha i}^{*}\left(x^{*}\right) P_{\beta i}^{*}(x)
$$

where

$$
x^{*}=\frac{x}{a}, \quad y^{*}=\frac{y}{b}, \quad w_{i}^{*}\left(x^{*}, y^{*}\right)=\frac{w_{i}}{H\left(x^{*}, y^{*}\right)}
$$

$G$ is a normalization scaling factor given by:

$$
G=\sqrt{\iint\left(X_{\alpha i}^{*}\left(x^{*}\right) Y_{\beta i}^{*}(x)\right)^{2} \mathrm{~d} x^{*} \mathrm{~d} y^{*}}
$$


Scientific Research Publishing (SCIRP) is one of the largest Open Access journal publishers. It is currently publishing more than 200 open access, online, peer-reviewed journals covering a wide range of academic disciplines. SCIRP serves the worldwide academic communities and contributes to the progress and application of science with its publication.

Other selected journals from SCIRP are listed as below. Submit your manuscript to us via either submit@scirp.org or Online Submission Portal.
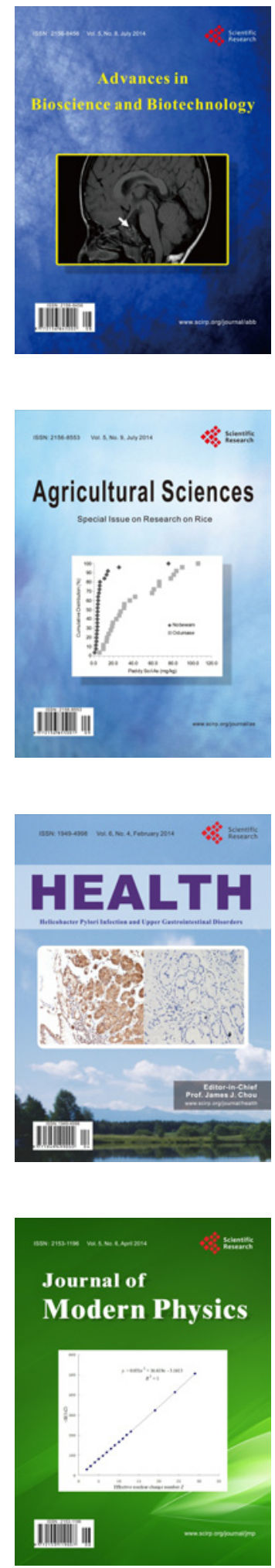
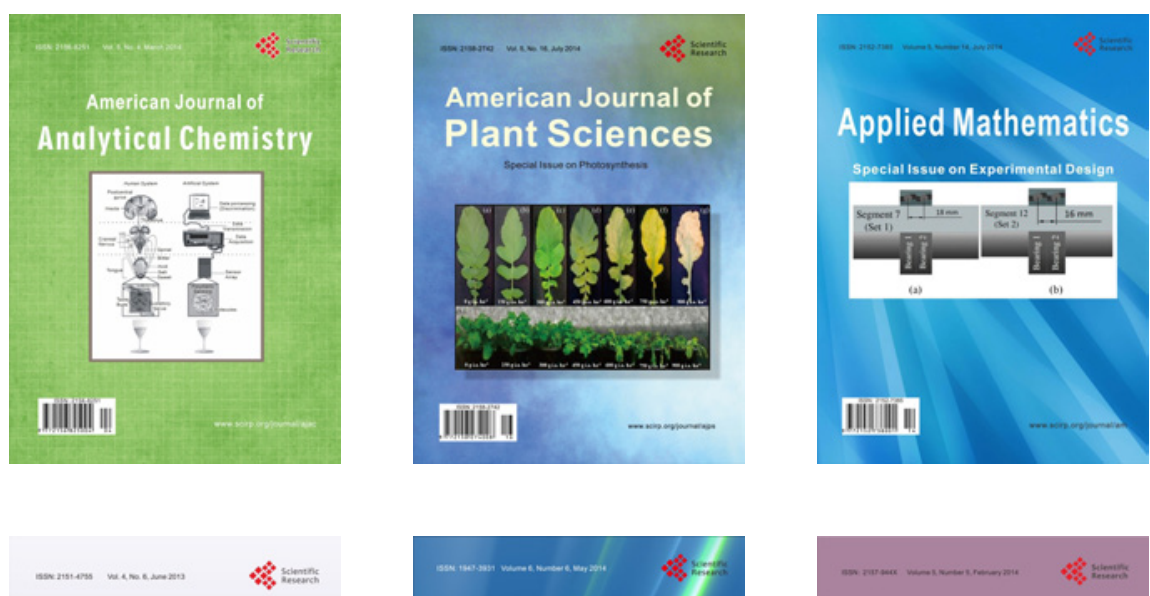

Creative Education
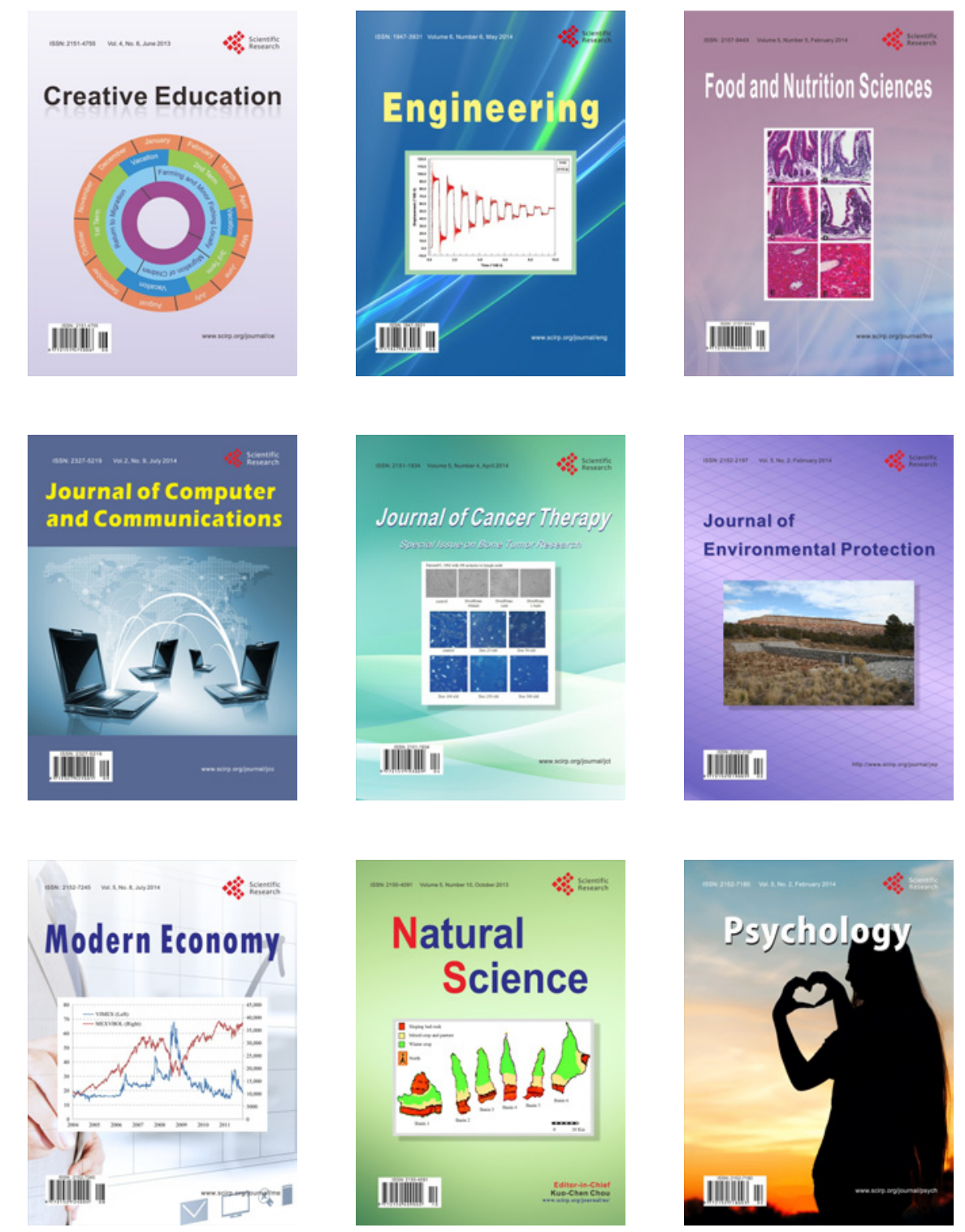